\title{
Consistent Valuation Cash Flow
}

\author{
Uzi Yaari $^{\mathrm{a}^{*}}$, Andrei Nikiforov ${ }^{\mathrm{a}}$, Emel Kahya ${ }^{\mathrm{a}}$, Yochanan Shachmurove ${ }^{\mathrm{b}}$ \\ ${ }^{a}$ Rutgers School of Business Camden, Rutgers University, Camden, NJ, 08003 \\ ${ }^{b}$ City College of the City University of New York, New York, NY, 10031
}

November 29, 2011

Revised: April 4, 2012

\begin{abstract}
This paper seeks to draw attention to a flaw in the firm's Free Cash Flow model and related statement widely accepted in Corporate Finance. We argue that the common offset of any Current Liabilities against Current Assets distorts the FCF size, composition, and volatility, thereby misstating the firm or project size, debt and assets composition, financial leverage, risk profile, and estimated value. We demonstrate empirically that the offset opens opportunities to manipulate the FCF by systematically overstating its size and understating its volatility. We propose to avoid any offset and rename the standardized statement "Valuation Cash Flow" (VCF).
\end{abstract}

JEL classification: G30, G31, G32, G35, G38, H32, K22, L21, M14, M40, M41

Keywords: Financial Reporting, Free Cash Flow, Net Working Capital, Cost of Capital, Corporate Valuation, Project Valuation 


\section{Introduction}

The statement of Free Cash Flow (FCF) presented in modern corporate finance is designed to provide essential data for firm valuation. Consistent with finance methodology, this statement should present cash flow components generated (absorbed) by the firm's Operations and Investment activities against components of the same flow received (paid) by the Debt and Equity claimholders financing the firm. In a significant deviation from this rule, the common textbook presentation has the periodic change in Current Liabilities (CL), or a significant portion thereof, simultaneously subtracted from the periodic changes in Debt claims and Current Assets (CA), redefining the latter as a change in Net Working Capital (NWC). As a result, the explicit truncation of the FCF generated by the firm's assets and received by claimants is associated with implicit distortions of the firm's size and short-term growth rate, debt and asset compositions, financial leverage, and risk profile. The same applies to individual projects. Apparently replicating the accounting-based Statement of Cash Flow (SCF), the underlying offset of assets against liabilities (hereafter "the offset") is inconsistent with financial-economic methodology and invites manipulation of the firm's FCF and estimated market value. Our empirical analysis shows that the offset makes the FCF systematically larger and less volatile. An average sample of 1,220 U.S. public corporations over 22 years (1988-2009) reveals that the offset overstates the FCF mean by $33.7 \%$ and median by $128.2 \%$. This result is explained by the typically large portion of total Liabilities made up of current Liabilities, representing $19.8 \%$ in the average firm and $24 \%$ in the median firm. We propose an offset-free Valuation Cash Flow (VCF), which eliminates those distortions and associate incentive for manipulations. 
U.S. firms are currently free to design and publish their own FCF reports. Since our study does not rely on data of such reports but on official Income Statement and Balance Sheet filings, our analysis is limited to identifying potential gainful manipulations facilitated by the offset. Our expectation of such manipulations is based on a body of accounting theory and related evidence concerning financial statements in general ${ }^{1}$.

Adhikari and Duru (2006) compare and contrast voluntary FCF statements designed by the firms themselves to be published side-by-side with their mandatory 10-K and 10-Q financial statements over the period 1994-2004. Firms that engage in FCF disclosure are found to pay higher dividends, but are more leveraged, less profitable, and have a lower credit rating than matched non-disclosing firms. The same pattern is observed in the behavior of individual firms over time: Years of FCF disclosure are associated with higher dividends, higher leverage, and lower profitability. In other words, poorly-performing firms have both an incentive and a legal permission to design and publish their own FCF report side-by-side with their official financial reports, thereby mitigating the undesirable impact of the latter! The same bias is found by Wasley and Shuang Wu (2006) who investigate the effect of Regulation FD (Full Disclosure). Introduced in 2000 , this increasingly popular regulation states that dissemination of voluntary cash flow forecasts (not to be confused with FCF statements) must be via publication rather than private distribution. Management uses those forecasts to disclose good news of cash flow to mitigate the negative impact of bad news of earnings.

Our paper proceeds as follows. Part 2 traces the erroneous FCF offset to the different finance and accounting methodologies. Part 3 analyzes conceptual errors and implied distortions inherent to the FCF offset. Part 4 tests for opportunities to manipulate the offset-based FCF by comparison to the offset-free VCF. Part 5 offers a summary and conclusions.

\footnotetext{
${ }^{1}$ See Hackel and Livnat (1992)
} 


\section{Free Cash Flow and the Accounting Statement of Cash Flow}

Cognizant of developments in capital budgeting, portfolio theory, and corporate valuation, the U.S. Financial Accounting Standards Board (FASB 95, 1987) and the International Accounting Standard Board (IAS 7, 1991) each introduced a mandatory Statement of Cash Flow (SCF). One objective of this reform was to supplement traditional statements based on accruals by a uniform, simplified report containing more objective, investor-oriented cash flows. Nevertheless, consistent with traditional accounting methodology, the focus of the new statement is the functioning of the firm itself, not the immediate performance of its claimants. This orientation is emphasized by the SCF bottom line, the periodic change in the amount of cash and equivalents held by the firm!

The methodological conflict between the VCF and SCF is revealed by their different way of measuring the firm's performance. The VCF focuses on market value, which is determined by the firm's net cash flow vis. its equity and debt claimholders. In this context, the firm's Operations are an important source of cash flow, positive or negative, and therefore treated as related activities. Depending on management policy and other factors, the VCF in the single year often does not match the current Operating cash flow. In contrast, the SCF focuses on the firm's Operations and treats certain short-lived assets (Investment) and Liabilities (Financing) as overlapping activities. Both approaches are valid in their own context. The contribution of the VCF lies in its power to measure the periodic cash flows to and from the firm's claimholders and estimate the value of the firm or its individual project from the perspective of those funding it. 


\section{The Offset Rationale}

\subsection{FCF Distortion}

The textbook FCF statement subtracts the periodic cash flow of all or part of Current Liabilities (CL) from the cash flow generated by Current Assets (CA), juxtaposing any remaining CL and a composite asset identified as Net Working Capital. Our survey of finance textbooks revealed the following justifications for the offset.

(1) "Current Liabilities have a short life." Since the company is viewed as a going concern, the focus must be on the flow generated by contracts of any maturity. Short-term contracts roll over more frequently, but remain a component of the firm's debt.

(2) "Current Liabilities pay no interest." This statement implies a systematic free lunch. It overlooks interest paid on CL explicitly, as in long-term coupon bonds approaching maturity, or implicitly, as in Accounts Payable that offer a discount on early repayment ${ }^{2}$. A financial claim of zero or negative interest would still be a claim against the company.

(3) "Since a dollar of CL is a mirror image of a dollar of CA, the two can be conveniently restated as a net asset, NWC (usually CL $<$ CA)." Underlying this claim is the strong assumption that a dollar increase in CA is economically equivalent to a dollar decrease in CL. Such symmetry is inconsistent with economic logic or casual observation for the following reasons:

a. The firm has less control over repayment of its loans to customers as it has over repayment of its debt to suppliers.

\footnotetext{
${ }^{2}$ See Petersen and Rajan, 1997
} 
b. The offset is likely to distort the firm's stated FCF.

c. The offset opens the door to manipulating Current Liabilities to smooth and overstate the firm's FCF, leading to overstatement of its estimated market value.

\subsection{Assets, Liabilities, and Risk Distortions}

(1) Like FCF calculations, empirical studies of capital structure often ignore CL or the subset of trade credit, implicitly offsetting them against CA. We question the rationale behind this practice. The offset directly distorts the firm's measured Debt/Equity and Long-Term/Short-Term debt ratios ${ }^{3}$.

(2) The offset hides but does not eliminate the default risk attached to short-term liabilities. The offset understates the firm's leverage.

(3) The offset distorts the firm's measured financial risk by changing the overall risk profiles of its assets and liabilities.

Whether at the level of the firm or the individual project, FCF often distort past and projected cash flows, their level of risk, and their implied value. The cost of such manipulations and implied misinformation is shared by the firm's claimants, employees, and other stakeholders. This cost is avoided by our offset-free version of the FCF.

\section{Empirical Evidence}

Most textbooks define FCF as follows:

$$
F C F=E B I T\left(1-T_{c}\right)+\text { Depreciation }- \text { Taxes }- \text { Capital Expenditures }- \text { Change in NWC }
$$

\footnotetext{
${ }^{3}$ This error is avoided by some authors, more recently Levy and Sarnat (1990), Kahya et al. (1992), Weston and Copeland (1992), Lemmon et al. (2008), and Welch (2010).

${ }^{4}$ With greater detail and reference to actual COMPUSTAT items, Free Cash Flow with full offset $(\mathrm{FCF}(\mathrm{F}))$ is calculated as the sum of net cash flows from operations (excluding deferred taxes, extraordinary items, and interest paid) plus net cash flows from investing activities, minus increase in cash and marketable securities, plus exchange rate effect:
} 
where EBIT stands for earnings before interest and tax. The change in Net Working Capital $(\triangle \mathrm{NWC})$ includes full or partial offset of Current Liabilities against Current Assets, and is calculated by

$$
\Delta N W C_{t}=\left\{\left(C A_{t}-C A_{t-1}\right)-\left(C L_{t}-C L_{t-1}\right)\right\}
$$

where CA and CL stand for Current Assets and Current Liabilities, respectively, the content of CA remains intact, and the content of CL may vary for the purpose of manipulating the FCF. Changes in NWC and FCF are subject to full or partial offset, depending on whether the offset includes or excludes short-term "unfunded" debt. Since the publication of FCF statements by U.S. firms is voluntary, and the FCF content is left to the individual firm and can be changed over time, the range of potential FCF manipulations is significant. Our tests do not presume that firms in our sample were fully aware of the opportunity for manipulations.

\subsection{Data and Methodology}

Data used in this study are from two sources. The accounting information is obtained from the COMPUSTAT annual dataset, and the stock market information is from the CRSP monthly stock file. To ensure consistency in reported numbers and provide adequately long time series, we include all publicly-traded firms in the 22 year period from 1988 to 2009 .

In Figure 1, the graphs and related data present side-by-side the annual FCF and VCF of Chevron Corporation over two decades. Chosen as an example for its common features, this case demonstrates a firm's flexibility in manipulating the offset-based FCF in terms of its size and volatility. We have no evidence that Chevron Corporation took advantage of that opportunity.

\footnotetext{
FCF $(F)=$ Net Cash from Operations (308) - Deferred Taxes (126) - Interest Paid (315)

- Extraordinary Items (124) + Net Cash from Investing Activities (311) + Interest paid

- Increase in Cash (274) + Exchange Rate Effect (314) + $\Delta$ in ST Debt (301)

Numbers in parentheses represent item identifiers in the COMPUSTAT annual file. The Net Cash flow from operations includes changes in Net Working Capital, and the addition of changes in Short-term Debt insures the full-offset.
} 
The full and partial offset flows (FO, PO) respectively shown as dotted curves at the top and bottom graphs, are subject to management discretion and potential manipulation. The offset flows equal the modification in the firm's CL and CA flows, and therefore the vertical shift in the overall $\mathrm{FCF}^{5}$ (FOCF, POCF) shown as segmented curves. The offset impact is measured by the vertical distance between each version of the FCF and the offset-free VCF shown as a solid curve common to both graphs. A positive difference FCF-VCF measures an overstatement of the firm's performance as seen under full offset in 2001: The positive value of the dotted FO curve equals the positive difference between FOCF and VCF, namely $\$ 3,088=\$ 7,422-\$ 4,334$ million. In 2002, a small positive offset causes $\$ 35=\$ 2,873-\$ 2,838$ million. In 2003 , a negative offset causes FOCF smaller than VCF, $-\$ 3,386=\$ 7,090-\$ 3,704$ million. The small difference average flow between FOCF and POCF, and in relation to VCF is explained by the small average offset under both versions. A further comparison among the three versions of FCF reveals that the offset generally mitigated FCF volatility.

The basic economic relationship among the three curves, VCF vis. FOCF or POCF, can be summarized as follows. (1) The level and changes of VCF are the basic factors determining FOCF (or POCF); (2) FO (or PO) modifies the level and changes of FOCF (or POCF); specifically, (3) FOCF (or POCF) runs above VCF if FO (or PO) is positive; or below VCF if FO (or PO) is negative. In short, the condition offset $>0$ causes FCF $>\mathrm{VCF}$, and the condition offset $<0$ causes $\mathrm{FCF}<\mathrm{VCF}$.

The 12 histograms in Figure 2 displaying the distribution of the ratio (FOCF - VCF) / |VCF| across firms in 6 U.S. industries during years 1988 and 2008 convey the following salient features:

\footnotetext{
${ }^{5}$ Note that an apparent increase in the firm's FCF can be achieved without increasing the firm's debt (1) by expanding the set of CL accounts subject to offset, or (2) by compensating for any increase in offset borrowing by a decrease in non-offset debt of short or medium term.
} 
(1) Even within industries, the errors of FCF vis. VCF are systemic and robust but not ordered.

(2) The mode statistic of distributions within industries is close to zero, the point of parity between FOCF and VCF. The graphs do not indicate the relationship FOCF $>$ VCF, suggesting the absence of significant FCF size manipulations by firms in those industries. The graphs demonstrate a widespread neglected opportunity to gain from overstatement of the FCF through the use of an offset ${ }^{6}$. (3) Limited to one method, firms above parity would prefer the FOCF for its flexibility in promoting a good image. (4) Firms positioned significantly below parity would prefer the VCF. (5) There is no presumption that the first group of firms is economically superior. (6) All firms would prefer the current regime of a flexible FCF with voluntary reporting.

Table 1 provides basic descriptive statistics of our sample of publicly-traded firms. There are over 26.8 thousands firm-year observations with an average of 1,340 unique firms per year. The average firm's assets size is about $\$ 750$ million, with Current Assets of $\$ 200$ million (26\% of total assets) and Current Liabilities of $\$ 150$ million (19.7\% of total assets). If all current debt (including the short-term portion of long-term debt) is removed from Current Liabilities, the remainder would still represent a substantial amount relative to Total Assets ( $\$ 112$ million or $15 \%)$.

The large amounts and relative values of current assets and liabilities result in economically significant differences between the three versions of the FCF - a full offset, a partial offset, and no offset of CL against CA. While each of the three versions has a positive mean, the median VCF is negative, implying that the other versions overstate the FCF of the median firm. In dollar values, the average FCF with full offset exceeds the VCF by more than $\$ 5$ million per year (33.7\%). The more popular FCF with a partial offset artificially increases the

\footnotetext{
${ }^{6}$ The absence of widespread corporate manipulation should make it easier for policymakers to switch to VCF.
} 
average cash flows to claimholders by almost $\$ 4$ million per year (26.1\%). The Median and Mean annual FCF at the level of the firm increases monotonically from VCF to FOCF, namely FOCF $>$ POCF $>$ VCF, implying the same order in dollar and relative terms. In contrast, the volatility of FCF as measured by the CV increases monotonically from FOCF to VCF. The combination of the two features is confirmed by the common preference of firms for FOCF or POCF. The offset facilitates low-cost enhancement and stabilization of the voluntary FCF.

The effect of the offset as measured by the Relative Difference is far greater in small median_firms as opposed to large firms about the mean. The same is true for Full and Partial offsets.

Table 2 depicts the dynamics of the three versions of FCF year-by-year from 1988 to 2009. During the first 13 years, the full-offset and partial-offset FCF exhibit systematically higher values than the VCF. The year 2000 records the largest differences between the offsetbased FCF and VCF: over $200 \%$ ! The most plausible explanation is the bubble in equity market prices. As equity values rose during 1999 and 2000, firms gradually increased their liabilities, including Current Liabilities, to maintain an optimal capital structure. As the market collapsed in 2001 the FCF-VCF difference dropped sharply and became negative, encouraging companies to reverse the process by paying off Current Liabilities. A similar pattern repeated itself in the housing market bubble of 2007-2009.

Despite the systematic ordering FOCF $>\mathrm{POCF}>\mathrm{VCF}$ in large and small firms, an individual firm's POCF can be larger or smaller than the parallel FOCF in any given year, depending on the sign of the incremental CL offset. This suggests that a switch across versions of FCF should be viewed as form of manipulation that can affect financial appearance. In addition, both the mean of larger firms and the median of smaller ones show that the positive 
Serial Correlation across years is highest under FOCF and lowest under VCF. These statistics confirm the advantage of smoothing facilitated by the current-liabilities offset, one element of the FCF manipulation. A higher annual Standard Deviation of VCF is common only in smaller, less diversified firms.

Table 3 displays value differences among the three versions of FCF for 25 industry groups, based on GICS industry classification standards. The FCF size ranking of FOCF $>\mathrm{POCF}>\mathrm{VCF}$ at the level of the firm is preserved within individual industries, reconfirming the reliable advantage of the CL offset in that context.

The advantage of avoiding VCF may vary significantly across industries. Industries with the largest differences between offset and non-offset FCF are food companies and retailers, followed by telecoms and utilities. The groups with the smallest differences are banks, financials, real estate, and insurance companies. Companies that rely more on trade credit (food and retailers) would gain more by a greater offset, namely a greater distortion in their valuation. The valuation of financial institutions would be affected the least.

Table 4 explores the effect of firm size on differences among the three versions of FCF. To determine the effect of size, we divide our sample of over 26 thousand firm-year observations into 5 size quintiles with an approximately equal number of observations in each. A positive (negative) offset difference would improve (damage) the firm's cash flow appearance regardless of whether VCF is positive or negative. As seen in the two smallest quintiles, the systematic negative offset difference deprives such firms of access to this reporting advantage. In contrast, the dollar and relative offset differences in the three largest quintiles is systematically positive and large, suggesting overstatement of FCF and estimated value. 
Table 5 reports pair-wise correlations among the three versions of FCF. We see that all pairs exhibit relatively high correlation above 90 percent with 95\% Pearson confidence interval. The highest correlation is between VCF and FCF with partial offset. The lowest correlation is between VCF and FCF with full offset. Spearman correlations exhibit the same pattern but with lower values in the 70's and 80's due to its non-parametric nature.

The high correlation across versions of FCF explains the low cost of manipulation. A positive offset would boost FCF and with it the firm's financial appearance without significantly modifying FCF volatility. This explains the absence of a serious challenge to different versions of FCF.

\section{Summary and Conclusion}

The immediate objective of this paper is to correct the FCF version adopted by corporate finance textbooks and preached for over two decades. This version calls for the offset of Current Liabilities against Current Assets, leading to the offset of their flows. We demonstrate that the offset can significantly distort the FCF in terms of size, composition, and volatility; leading to additional distortions in the firm or project size, debt and assets composition, financial leverage, risk profile, and estimated value. Our empirical analysis suggests that firms prefer the offsetbased FCF for its greater flexibility in projecting elevated FCF size and stability. Our narrowed definition of FCF eliminates this flexibility. The offset-free VCF is a logical substitute which would moderate the appetite for financial manipulation and better serve insiders and outsiders by providing more accurate and unbiased information. 


\section{References}

Adhikari, A., Duru, A., 2006. Voluntary disclosure of free cash flow information. Accounting Horizon. 20, 311-332.

Hackel, K. S., Livnat, J., 1992. Cash flow and security analysis. Business One Irwin, New York.

Kahya, E., Palmon, D. and Yaari, U., 1992. "Statement of Cash Flows for Decision-Making." Working Paper. pp.1-20. Presented on November 20, 1992, at the Accounting and Finance Workshop, School of Business, Rutgers University-Camden.

Lemmon, M. L., Roberts, M. R., Zender, F. J., 2008. Back to the beginning: persistence and the cross-section of corporate capital structure. The Journal of Finance. 63, 1575-1608.

Levy, H., Sarnat, M., 1990. Capital investment and financial decisions, fourth ed. Prentice Hall, New York.

Petersen, M. A., Rajan, R. G., 1997. Trade credit: theories and evidence. Review of Financial Studies. 10, 661-691.

Wasley, C. E., Shuang Wu, J., 2006. Why do managers voluntarily issue cash flow forecasts? Journal of Accounting Research. 44, 389-429.

Welch, I., 2010. A bad measure of leverage: the financial-debt-to-asset ratio. Working Paper. Brown University.

Weston, J. F., Copeland, T. E., 1992. Managerial finance, ninth ed. Dryden Press, Fort Worth. 


\section{Figure 1}

VCF vs. FCF - Current Liabilities Offset Dynamics; Chevron Inc. 1988-2006. The figure shows the time series from 1988 to 2006 of three versions of the Free Cash Flow of Chevron Inc.: Full Offset of Current Liabilities against Current Assets (FOCF, top drawing), Partial Offset of Current Liabilities less shortterm debt against Current Assets (POCF, bottom drawing), and no liability offset, named Valuation Cash Flow (VCF, both drawings). The annual flow of Current Liabilities offset against Current Assets equals the vertical distance FOCF-VCF or POCF-VCF. All figures are in millions of dollars.
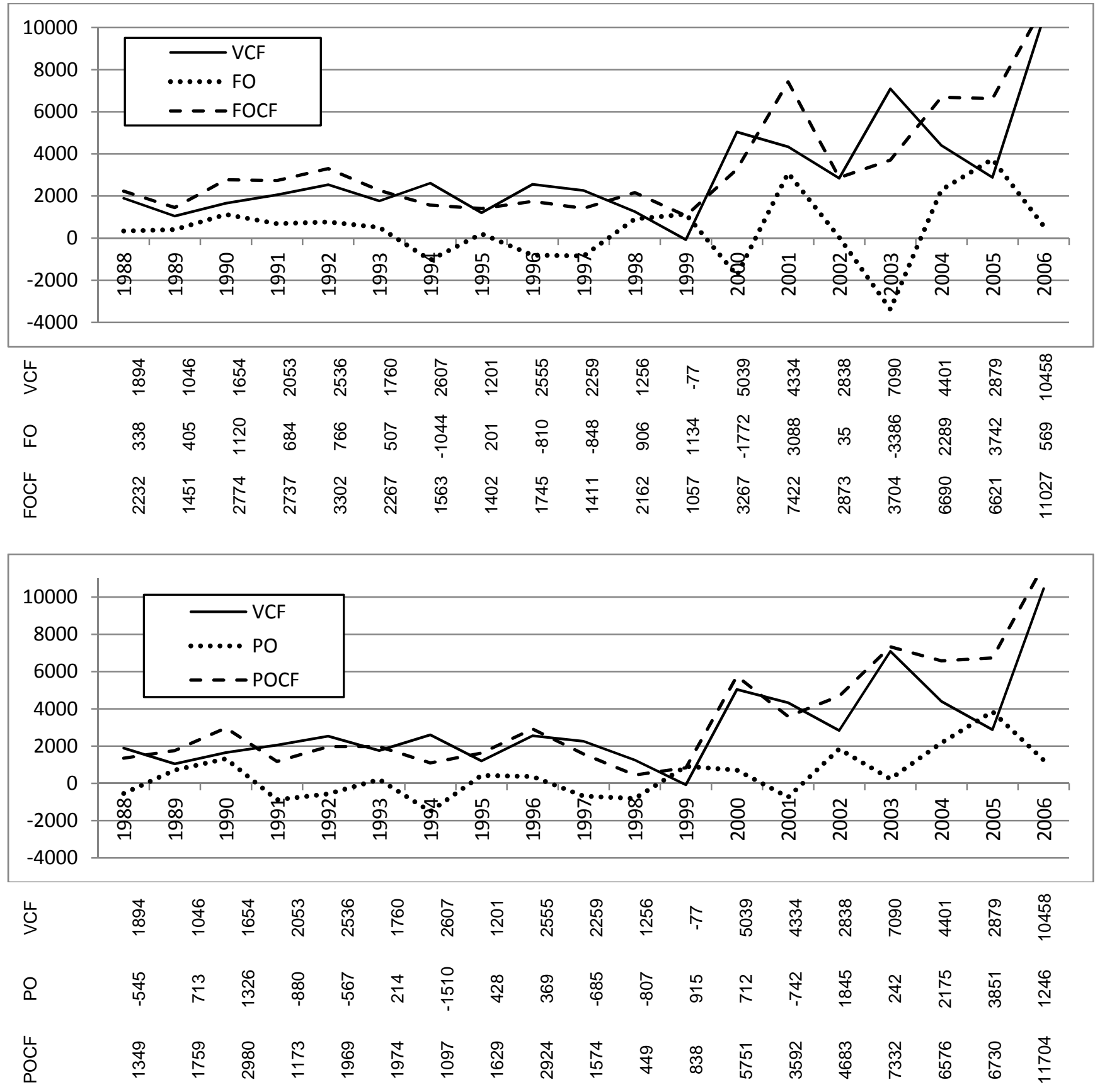


\section{Figure 2}

Distribution of the Ratio (FOCF-VCF) / |VCF| across Firms, 1988 and 2008. The figure shows the histograms of the distribution of differences between FOCF and VCF relative to the absolute value of the VCF for six selected industries for two years: 1988 and 2008.

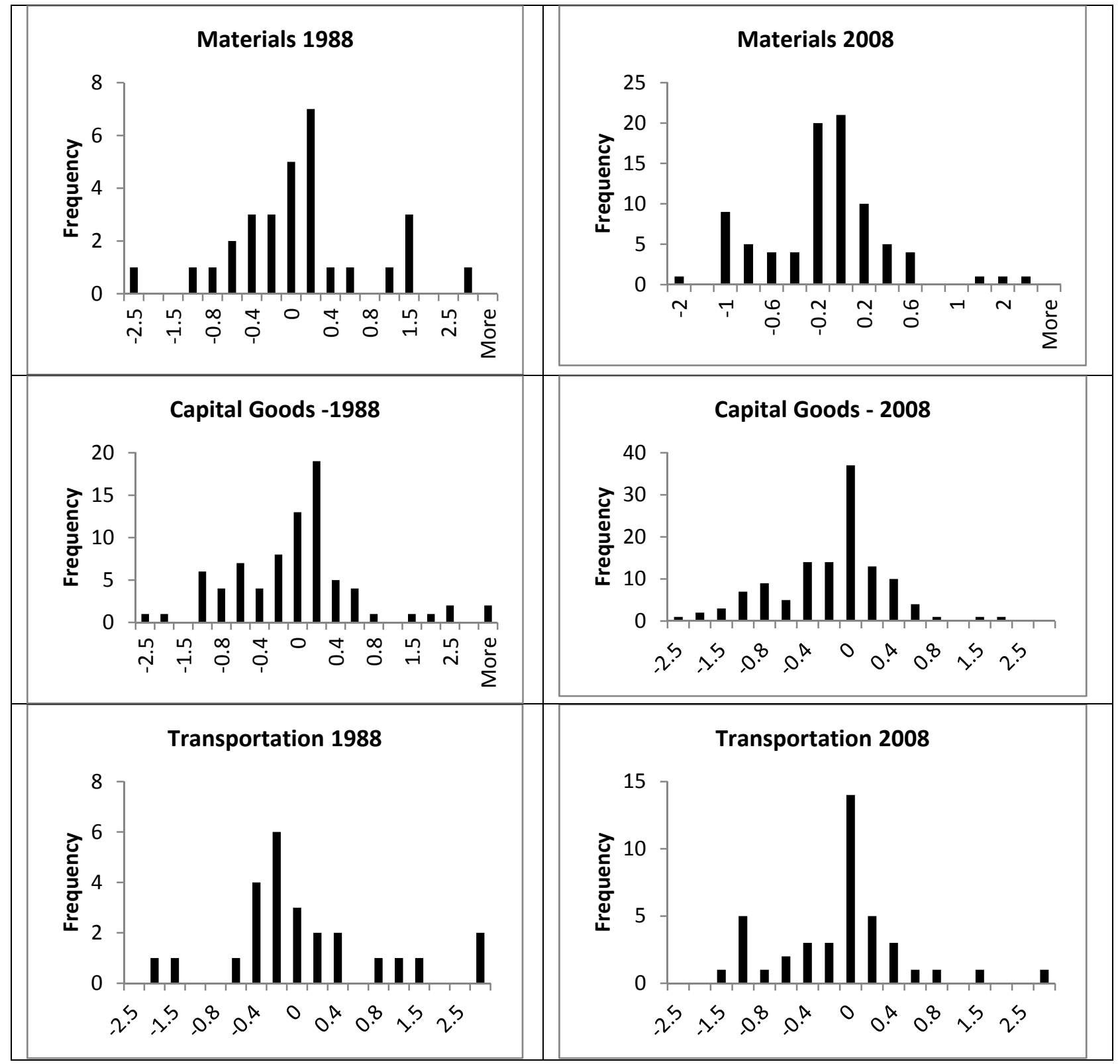




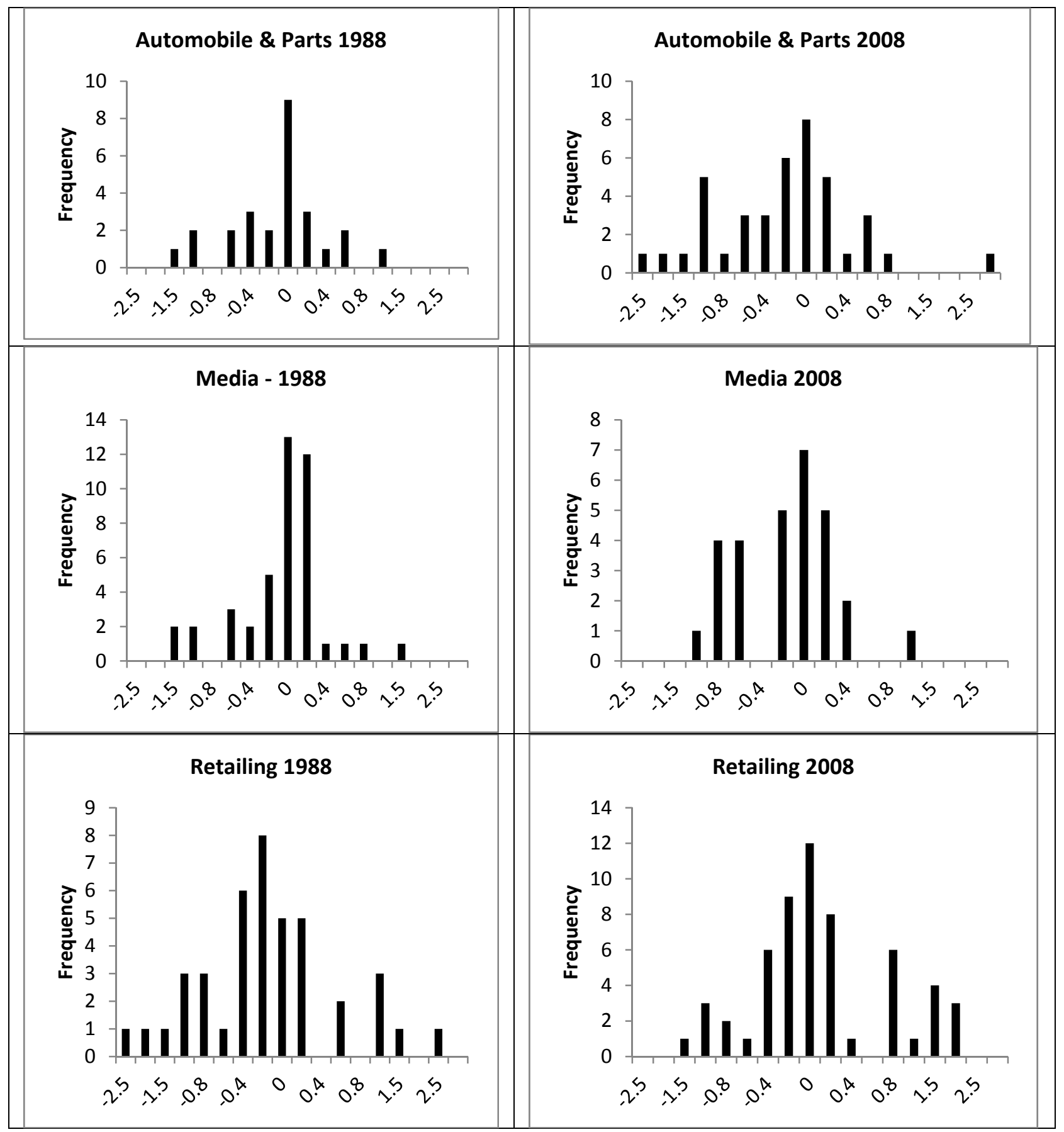




\section{Table 1}

Descriptive Statistics of VCF and Competing Versions of Free Cash Flow, 1988-2009. The table shows the median and mean of the three versions of Free Cash Flows (FCF): with full offset of Current Liabilities against Current Assets (FOCF), with partial offset of Current Liabilities excluding Short-Term Debt against Current Assets (POCF), and without offset of Current Liabilities against Current Assets, VCF, or Valuation Cash Flow. CA=total Current Assets, $\mathrm{CL}=$ total Current Liabilities, $\mathrm{DCL}=$ short-term Debt in Current Liabilities, $\mathrm{CV}=$ Coefficient of Variation. The Relative Difference between flows is calculated as the ratio of the difference between the means of either FOCF and VCF, or POCF and VCF, divided by the absolute value of VCF. All non-percentage values are in millions of dollars.

\begin{tabular}{lrrr}
\hline Variable & Median & Mean & CV \\
\hline Annual Flow: & & & \\
FOCF $=$ VCF $+\Delta C L$ & 0.04 & 20.28 & 6.63 \\
POCF $=$ VCF $+\Delta$ CL- $\Delta$ DCL & 0.00 & 19.12 & 6.94 \\
VCF & -0.13 & 15.17 & 8.79
\end{tabular}

Flow Difference:

$\begin{array}{lll}\mathrm{FOCF}-\mathrm{VCF}=\triangle \mathrm{CL} & 0.1635 & 5.112443 \\ \mathrm{POCF}-\mathrm{VCF}=\triangle \mathrm{CL}-\triangle \mathrm{DCL} & 0.1275 & 3.956955\end{array}$

Relative Flow Difference:

$\begin{array}{lll}\text { (FOCF - VCF) } /|\mathrm{VCF}| & 128.2 \% & 33.7 \% \\ \text { (POCF }-\mathrm{VCF}) /|\mathrm{VCF}| & 100.0 \% & 26.1 \%\end{array}$

Year-End Value:

$\begin{array}{llll}\text { Total Assets } & 56.15 & 748.45 & 2.59\end{array}$

$\begin{array}{lll}\text { Total Current Assets } & 29.17 & 197.44\end{array}$

$\begin{array}{llll}\text { Total Current Liabilities } & 13.45 & 147.87 & 2.60\end{array}$

$\begin{array}{llll}\text { Total Debt in Current Liabilities } & 0.77 & 35.88 & 3.52\end{array}$

$\mathrm{N}=26,864$ firm years. 
Table 2

Time Pattern of Three Free Cash Flows, 1988-2009. The three FCF versions are with full offset of current liabilities against current assets (FOCF), with partial offset of current liabilities excluding short term debt against current assets (POCF), and without offset of current liabilities against current assets, VCF, or Valuation Cash Flow. The relative difference between flows is calculated as the ratio of the difference between the means of either FOCF and VCF, or POCF and VCF, divided by the absolute value of VCF. The Coefficient of Variation, $\mathrm{CV}$, is presented in absolute value. All non-percentage values are in millions of dollars.

\begin{tabular}{|c|c|c|c|c|c|c|c|c|}
\hline \multirow[b]{2}{*}{ Year } & \multicolumn{3}{|c|}{ Medians } & \multicolumn{3}{|c|}{ Means } & \multicolumn{2}{|c|}{ Relative Difference } \\
\hline & FOCF & POCF & $\mathrm{VCF}$ & FOCF & POCF & $\mathrm{VCF}$ & FOCF & POCF \\
\hline 1988 & 0.87 & 0.72 & 0.31 & 44.85 & 44.21 & 37.91 & $18 \%$ & $17 \%$ \\
\hline 1989 & 0.76 & 0.52 & 0.20 & 38.26 & 33.73 & 25.49 & $50 \%$ & $32 \%$ \\
\hline 1990 & 1.17 & 0.94 & 0.59 & 42.82 & 37.02 & 33.57 & $28 \%$ & $10 \%$ \\
\hline 1991 & 1.01 & 1.16 & 1.12 & 37.04 & 39.28 & 38.00 & $-3 \%$ & $3 \%$ \\
\hline 1992 & 0.34 & 0.20 & 0.06 & 26.25 & 24.63 & 22.00 & $19 \%$ & $12 \%$ \\
\hline 1993 & 0.12 & 0.07 & -0.01 & 32.08 & 32.41 & 29.46 & $9 \%$ & $10 \%$ \\
\hline 1994 & 0.21 & 0.13 & -0.03 & 35.77 & 34.64 & 29.70 & $20 \%$ & $17 \%$ \\
\hline 1995 & 0.20 & 0.06 & -0.07 & 32.13 & 30.71 & 25.39 & $27 \%$ & $21 \%$ \\
\hline 1996 & 0.10 & 0.00 & -0.21 & 26.86 & 26.46 & 20.44 & $31 \%$ & $29 \%$ \\
\hline 1997 & 0.01 & -0.02 & -0.27 & 20.38 & 17.56 & 14.42 & $41 \%$ & $22 \%$ \\
\hline 1998 & 0.00 & -0.05 & -0.32 & 19.39 & 17.42 & 13.93 & $39 \%$ & $25 \%$ \\
\hline 1999 & 0.01 & -0.01 & -0.23 & 19.35 & 12.45 & 8.32 & $133 \%$ & $50 \%$ \\
\hline 2000 & 0.00 & -0.15 & -0.49 & 21.01 & 14.56 & 4.75 & $342 \%$ & $206 \%$ \\
\hline 2001 & 0.01 & 0.00 & -0.01 & 5.82 & 8.64 & 11.08 & $-47 \%$ & $-22 \%$ \\
\hline 2002 & 0.01 & 0.00 & 0.03 & 15.30 & 20.65 & 18.71 & $-18 \%$ & $10 \%$ \\
\hline 2003 & 0.00 & -0.01 & -0.11 & 12.15 & 15.42 & 13.50 & $-10 \%$ & $14 \%$ \\
\hline 2004 & -0.08 & -0.26 & -0.67 & 12.52 & 13.89 & 7.06 & $77 \%$ & $97 \%$ \\
\hline 2005 & -0.02 & -0.23 & -0.77 & 15.71 & 12.50 & 4.11 & $282 \%$ & $204 \%$ \\
\hline 2006 & 0.00 & -0.16 & -0.62 & 15.39 & 13.94 & 11.05 & $39 \%$ & $26 \%$ \\
\hline 2007 & -0.02 & -0.24 & -0.79 & 4.70 & 2.46 & -0.94 & $603 \%$ & $363 \%$ \\
\hline 2008 & 0.06 & 0.00 & -0.05 & 6.75 & 4.27 & 3.81 & $77 \%$ & $12 \%$ \\
\hline 2009 & 0.42 & 0.57 & 1.42 & 16.15 & 22.13 & 28.82 & $-44 \%$ & $-23 \%$ \\
\hline $\begin{array}{r}\text { Serial } \\
\text { Correlation }\end{array}$ & 0.84 & 0.70 & 0.53 & 0.85 & 0.77 & 0.67 & & \\
\hline $\begin{array}{r}\text { Standard } \\
\text { Deviation }\end{array}$ & 0.37 & 0.39 & 0.55 & 12.01 & 11.66 & 11.64 & & \\
\hline $\begin{array}{l}\text { Abs. Value } \\
\text { of CV }\end{array}$ & 1.58 & 2.63 & 13.10 & 0.53 & 0.54 & 0.64 & & \\
\hline
\end{tabular}

The number of firms $(\mathrm{N})$ varies from the lowest 644 in 1988 to the highest 1,732 in 2005, adding to a total of $\mathrm{N}=26,864$ firm years. 
Table 3

Free Cash Flows across Industry Groups, 1988-2009. The three FCF versions are with full offset of current liabilities against current assets (FOCF), with partial offset of current liabilities excluding short term debt against current assets (POCF), and without offset of current liabilities against current assets, $\mathrm{VCF}$, or Valuation Cash Flow. The relative difference between flows is calculated as the ratio of the difference between the means of either FOCF and VCF, or POCF and VCF, divided by the absolute value of VCF. Industry groups correspond to GICS industry classification standards. Mean values and their differences are in millions of dollars. All non-percentage values are in millions of dollars.

\begin{tabular}{|c|c|c|c|c|c|c|c|}
\hline Industry Name & Group & $\mathrm{N}$ & FOCF & Means & VCF & $\begin{array}{l}\text { Relative } \\
\text { (FOCF-VCF)/ } \\
\text { |VCF } \mid\end{array}$ & $\begin{array}{l}\text { Differences } \\
\text { (POCF-VCF)/ } \\
|\mathrm{VCF}|\end{array}$ \\
\hline Energy & 1010 & 1701 & -12.84 & -12.90 & -17.25 & $26 \%$ & $25 \%$ \\
\hline Materials & 1510 & 1527 & 28.18 & 28.41 & 26.14 & $8 \%$ & $9 \%$ \\
\hline Capital Goods & 2010 & 2537 & 13.60 & 11.65 & 8.59 & $58 \%$ & $36 \%$ \\
\hline $\begin{array}{l}\text { Commercial \& Professional } \\
\text { Services }\end{array}$ & 2020 & 1124 & 8.13 & 7.68 & 5.43 & $50 \%$ & $41 \%$ \\
\hline Transportation & 2030 & 368 & -1.55 & 1.17 & -6.08 & $75 \%$ & $119 \%$ \\
\hline Automobile \& Components & 2510 & 384 & 14.77 & 12.15 & 7.04 & $110 \%$ & $73 \%$ \\
\hline Consumer Durables \& Apparel & 2520 & 1485 & 18.53 & 17.97 & 15.34 & $21 \%$ & $17 \%$ \\
\hline Consumer Services & 2530 & 813 & 9.51 & 8.41 & 6.70 & $42 \%$ & $26 \%$ \\
\hline Media & 2540 & 586 & 11.12 & 9.55 & 4.36 & $155 \%$ & $119 \%$ \\
\hline Retailing & 2550 & 1100 & 18.91 & 16.95 & 5.90 & $221 \%$ & $187 \%$ \\
\hline Food \& Staples Retailing & 3010 & 203 & 92.02 & 93.41 & 77.32 & $19 \%$ & $21 \%$ \\
\hline $\begin{array}{l}\text { Food, Beverage \& Tobacco } \\
\text { Household \& Personal }\end{array}$ & 3020 & 731 & 48.96 & 45.27 & 41.22 & $19 \%$ & $10 \%$ \\
\hline $\begin{array}{l}\text { Products } \\
\text { Health Care Equipment \& }\end{array}$ & 3030 & 501 & 12.73 & 12.73 & 10.03 & $27 \%$ & $27 \%$ \\
\hline $\begin{array}{l}\text { Services } \\
\text { Pharmaceuticals, } \\
\text { Biotechnology \& Life }\end{array}$ & 3510 & 2179 & -1.44 & -1.31 & -3.33 & $57 \%$ & $61 \%$ \\
\hline Sciences & 3520 & 1880 & -6.06 & -6.16 & -7.23 & $16 \%$ & $15 \%$ \\
\hline Banks & 4010 & 6 & 0.02 & 0.11 & 0.08 & $-88 \%$ & $38 \%$ \\
\hline Diversified Financials & 4020 & 313 & 15.44 & 15.00 & 12.63 & $22 \%$ & $19 \%$ \\
\hline Insurance & 4030 & 78 & 0.79 & 2.35 & -0.39 & $303 \%$ & $703 \%$ \\
\hline Real Estate & 4040 & 199 & 2.18 & 2.10 & 1.67 & $31 \%$ & $26 \%$ \\
\hline $\begin{array}{l}\text { Software \& Services } \\
\text { Technology Hardware \& }\end{array}$ & 4510 & 2278 & -2.28 & -1.90 & -3.44 & $34 \%$ & $45 \%$ \\
\hline Equipment & 4520 & 2500 & -2.52 & -2.48 & -5.66 & $55 \%$ & $56 \%$ \\
\hline $\begin{array}{l}\text { Semiconductors \& } \\
\text { Semiconductor Equipment }\end{array}$ & 4530 & 752 & -1.85 & 0.40 & -3.35 & $45 \%$ & $112 \%$ \\
\hline Telecommunication Services & 5010 & 404 & 56.59 & 52.79 & 45.52 & $24 \%$ & $16 \%$ \\
\hline Utilities & 5510 & 2908 & 123.48 & 116.49 & 106.75 & $16 \%$ & $9 \%$ \\
\hline Unspecified Industry Group & & 438 & -12.49 & -12.58 & -13.05 & $4 \%$ & $4 \%$ \\
\hline
\end{tabular}

$\mathrm{N}=26,864$ firm years. 


\section{Table 4}

Free Cash Flows by Size Quintiles, 1988-2009. The three FCF versions are with full offset of current liabilities against current assets (FOCF), with partial offset of current liabilities excluding short term debt against current assets (POCF), and without offset of current liabilities against current assets, VCF, or Valuation Cash Flow. The relative difference between flows is calculated as the ratio of the difference between the means of either FOCF and VCF, or POCF and VCF, divided by the absolute value of VCF. All non-percentage values are in millions of dollars. Size quintiles are based on year-end market capitalizations obtained from the CRSP dataset.

\begin{tabular}{lrrrrr}
\hline & & \multicolumn{3}{c}{ Size Quintile } & \\
& 1=small & 2 & 3 & 4 & $5=$ big \\
\hline Annual Flow: & & & & & \\
FOCF $=$ VCF $+\Delta$ CL & -0.01 & -0.62 & -3.56 & 4.88 & 107.11 \\
POCF =VCF+ $\Delta$ CL- $\Delta$ DCL & -0.10 & -0.66 & -3.90 & 4.95 & 101.79 \\
VCF & 0.04 & -0.62 & -5.11 & 1.94 & 86.05 \\
& & & & & \\
Flow Difference: & & & & & \\
FOCF - VCF= $\Delta$ CL & -0.05 & -0.01 & 1.55 & 2.94 & 21.06 \\
POCF - VCF= $\Delta$ CL- $\Delta$ DCL & -0.14 & -0.04 & 1.21 & 3.01 & 15.74 \\
& & & & & \\
Relative Difference: & & & & & \\
(FOCF - VCF) / |VCF & $-121 \%$ & $-1 \%$ & $30 \%$ & $151 \%$ & $24 \%$ \\
(POCF - VCF) / |VCF| & $-343 \%$ & $-7 \%$ & $24 \%$ & $155 \%$ & $18 \%$ \\
& & & & & \\
Year-End Value: & & & & & \\
Total Assets & 23.98 & 81.71 & 200.76 & 643.72 & 3397.84 \\
Total Current Assets & 13.57 & 40.49 & 94.36 & 243.99 & 941.24 \\
Total Current Liabilities & 8.68 & 22.77 & 48.39 & 142.07 & 722.49 \\
Total Debt in Current Liabilities & 3.15 & 6.28 & 10.48 & 27.38 & 174.45 \\
\hline N=26,864 & & & & &
\end{tabular}

$\mathrm{N}=26,864$ 
Table 5

Correlation among the Three Versions of Free Cash Flow, 1988-2009. The correlations are Pearson and Spearman correlation coefficients with $95 \%$ confidence intervals. We calculate correlations for each firm and then equally-weight them to calculate the cross-sectional average. The three versions are: the FCF with full offset of total current assets by total current liabilities (FOCF), the FCF with partial offset of the total current assets by current liabilities without the short term debt (POCF), and the FCF with no offset which we call VCF (Valuation Cash Flow).

Pearson Correlation Statistics

\begin{tabular}{lllccc}
\hline Variable & Variable & $\mathrm{N}$ & $\begin{array}{c}\text { Correlation } \\
\text { Coefficient }\end{array}$ & 95\% Confidence Limits \\
\hline & & & & & \\
VCF & FOCF & 26,905 & 0.92 & 0.919 & 0.923 \\
VCF & POCF & 26,905 & 0.98 & 0.980 & 0.981 \\
FOCF & POCF & 26,905 & 0.94 & 0.940 & 0.943 \\
\hline
\end{tabular}

Spearman Correlation Statistics

\begin{tabular}{lllccc} 
Variable & Variable & $\mathrm{N}$ & $\begin{array}{c}\text { Correlation } \\
\text { Coefficient }\end{array}$ & 95\% Confidence Limits \\
\hline & & & & & \\
VCF & FOCF & 26,905 & 0.79 & 0.782 & 0.791 \\
VCF & POCF & 26,905 & 0.89 & 0.894 & 0.898 \\
FOCF & POCF & 26,905 & 0.87 & 0.865 & 0.871 \\
\hline
\end{tabular}

